\title{
Late results of mitral valve replacement using unstented antibiotic sterilised aortic homografts
}

\author{
S A QURESHI, M A HALIM, G CAMPALANI, Y J COE, M K TOWERS, M H YACOUB \\ From Harefield Hospital, Harefield, Middlesex
}

SUMMARY Three hundred and seventy nine patients who had undergone mitral valve replacement using unstented antibiotic sterilised aortic homografts were followed up for 52 to 138 months (mean 102 months). Patients requiring additional aortic valve replacement were excluded. The commonest cause was rheumatic heart disease (321 patients). There were 37 early deaths $(9.8 \%)$ and 97 late deaths $(28 \%)$. The actuarial survival of operative survivors was $83 \%$ at three years, $75 \%$ at five years, and $55 \%$ at nine years. Technical valve failure occurred in six patients $(1.6 \%)$, infective endocarditis in $19(5 \%)$, and degeneration of the valve in $43(12.5 \%)$. The cumulative probability of freedom from endocarditis was $96 \%$ at three years, $94 \%$ at five years, and $91 \%$ at nine years, while that of freedom from valve degeneration was $97 \%$ at five years and $48 \%$ at 10 years. There were no early embolic episodes, but late embolism occurred in five patients $(1.5 \%)$.

Although mitral valve replacement is an established procedure, the search for an ideal valve substitute continues because of the relatively high incidence of valve related complications. A technique for replacing the mitral valve by unstented aortic homografts was developed in 1968.' In this report we have analysed their long term performance.

\section{Patients and methods}

Between August 1969 and June 1977, 379 patients underwent replacement of the mitral valve using inverted unstented antibiotic sterilised aortic homografts. Patients requiring additional aortic valve replacement were excluded from this series. There were 137 men ranging in age between 24 and 72 years (mean 51 years) and 242 women ranging in age between 18 and 71 years (mean 50 years). The age and sex distribution is shown in Fig. 1. All patients were in NYHA classification class III or IV. The commonest cause of valve disease was rheumatic heart disease in 321 patients $(85 \%)$, followed by floppy valve syndrome in 42 patients $(11 \%)$, and ischaemic heart disease in 16 patients $(4 \%)$.

Three hundred and thirty one patients underwent isolated mitral valve replacement and 48 patients $(13 \%)$ had additional procedures. These included decortication of the left atrium in 17 patients, tricuspid valve replacement in 12 , tricuspid annuloplasty in

Accepted for publication 19 April 1983 six, coronary bypass grafting in 10 , and closure of an atrial septal defect in three patients (Table 1).

\section{TECHNIQUE}

The method of preparation and the technique of insertion of the aortic homograft have been described previously. ${ }^{2-4}$ The largest available aortic homograft (between $2.5 \mathrm{~cm}$ and $3 \mathrm{~cm}$ in diameter) was used. The valve was prepared at the time of operation by fixing it inside a flexible valve support of $35 \mathrm{~mm}$ Dacron tube with a collar of Dacron attached to one end. The diameter of the tube was larger than that of the homograft to allow for the proper expansion of the sinuses of Valsalva. The diseased mitral valve was excised, leaving a $2 \mathrm{~mm} \mathrm{rim}$. The homograft was then inserted by two suture lines, a lower interrupted everting mattress and an upper continuous which was used to refashion a new floor for the left atrium using autogenous pericardium. The left atrial appendage was excluded by the upper suture line which also covered the knots of the first suture line and the Dacron tube and ensured smooth blood flow from the pulmonary veins into the grafts without any areas of stasis or turbulence (Fig. 2). Prophylactic antibiotics were used for the first five days after operation. Anticoagulants were not used routinely.

FOLLOW-UP

Early death was defined as death occurring during the hospital admission for operation. Late death was defined as any death occurring after that. All patients 
Table 1 Additional procedures undertaken at time of operation ( $n=48$ ( $13 \%$ ) patients)

\begin{tabular}{lc}
\hline Procedure & No of patients \\
\hline Decortication of left atrium & 17 \\
Tricuspid valve replacement & 12 \\
Tricuspid annuloplasty & 6 \\
Coronary artery bypass grafting & 10 \\
Closing of atrial septal defect & 3 \\
\hline
\end{tabular}

were seen three to six months after operation and annually thereafter. Fifty three patients have been lost to follow-up. For the remaining patients, the followup ranged from 52 to 138 months (mean 102 months).

Valve failure was defined as valvar dysfunction necessitating reoperation or causing death regardless of aetiology. Degenerative failure was diagnosed when the homograft showed calcification, perforation, or disruption at reoperation or necropsy in the absence of previous endocarditis (Fig. 3). Technical failure was defined as dysfunction caused by detachment of the valve from the Dacron tube or distortion of the Dacron tube in the presence of normal valve leaflets.

Actuarial analysis of survival, valve failure, and thromboembolism was performed on the survivors of operation using the method described by Berkson and Gage. ${ }^{5}$ -

\section{Results}

\section{EARLY MORTALITY}

There were $37(9.8 \%)$ early deaths in the whole group. Of these, $27(8.2 \%)$ deaths occurred in the isolated mitral valve replacement group. The causes of early deaths were low output cardiac failure in 28 patients, renal failure in two patients, and pulmonary embolism in two patients. The remaining five deaths were the result of respiratory failure, dissecting aneurysm of the abdominal aorta, cerebrovascular accident, superior mesenteric artery occlusion, and acute early fungal endocarditis, respectively.

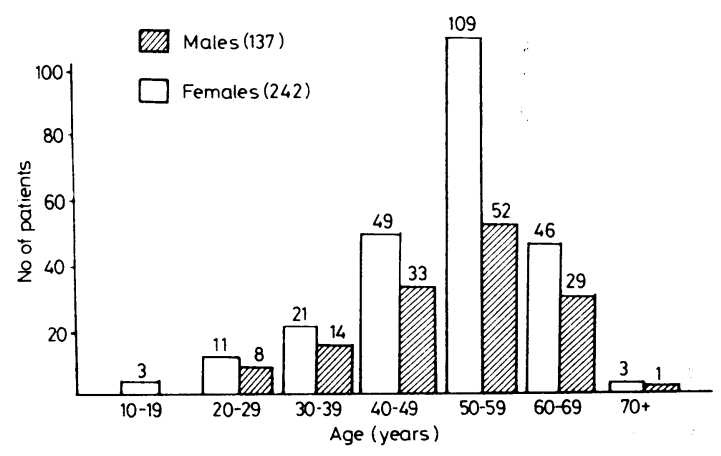

Fig. 1 Histogram showing age and sex distribution of patients undergoing aortic homograft replacement of the mitral valve.

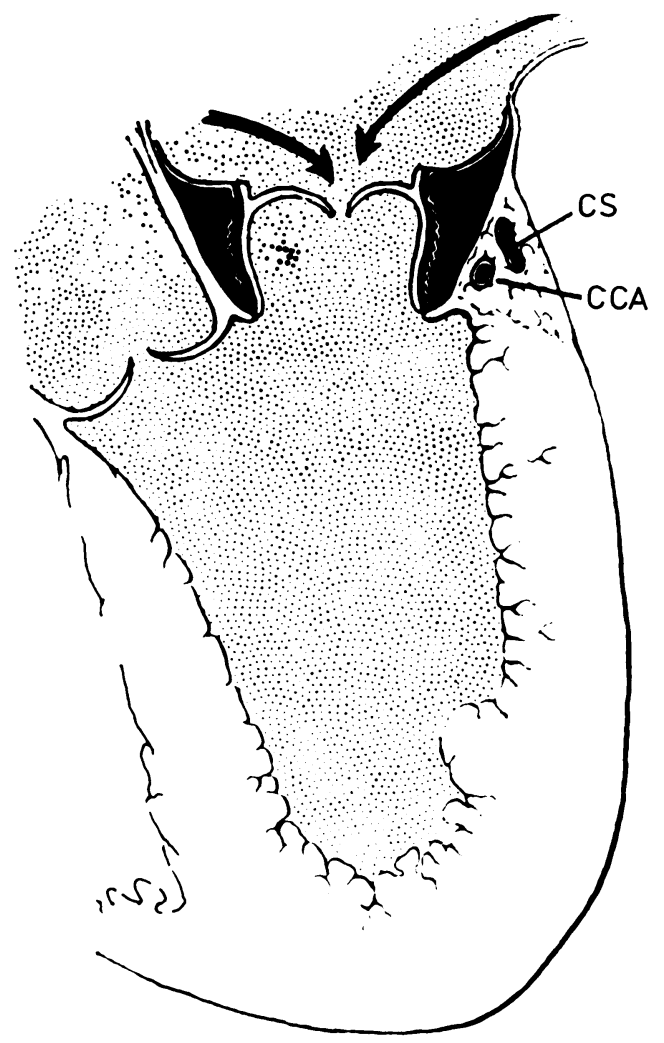

Fig. 2 Diagram showing the aortic homograft in the mitral position.

\section{LATE MORTALITY (Table 2)}

There were $97(28 \%)$ late deaths during a follow-up period of 52 to 138 months (mean 102 months). The cause of death was cardiac in 62 patients $(18 \%)$, miliary tuberculosis in four (1\%), and non-cardiac in 20 (6\%). In 11 patients the cause of death could not be determined. Of the cardiac causes, death was attributed to myocardial failure in 29 patients, homograft failure related to technical or degenerative causes in 18 patients, and infective endocarditis in 15 patients. The commonest cause of non-cardiac death was malignancy which occurred in nine patients.

The actuarial curve for the operative survivors showed a survival rate of $83 \%$ at three years, $75 \%$ at five years, and $55 \%$ at nine years (Fig. 4).

\section{THROMBOEMBOLISM}

There were no early embolic episodes during the first three months in spite of the fact that anticoagulants were not used routinely. Late systemic embolism occurred in five $(1.5 \%)$ patients at three, $31,40,42$, 


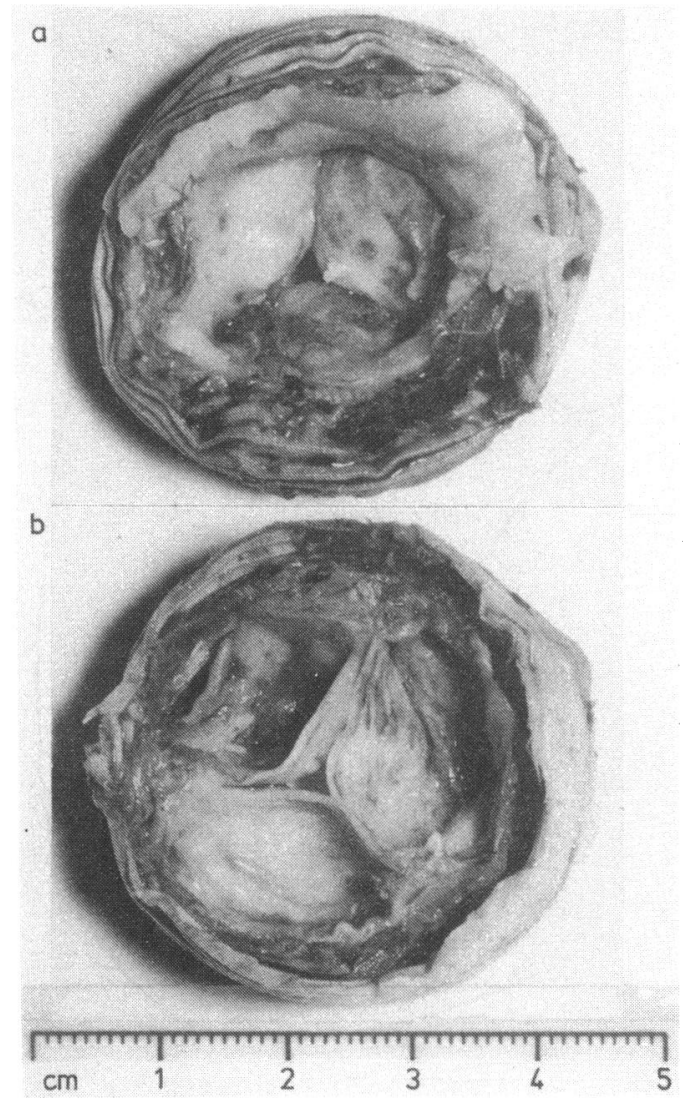

Fig. 3 Atrial (a) and ventricular (b) views of a degenerative aortic homograft removed nine years after operation.

and 61 months after operation. All these patients were subsequently anticoagulated with warfarin.

Actuarial analysis showed a predicted thromboembolism free rate of $98 \%$ at five years and $97.5 \%$ at nine years (Fig. 5).

\section{VALVE FAILURE \\ Technical}

Technical failure occurred in six patients (1.6\%). In four patients it occurred in the early postoperative period (within four months). These patients presented with acute pulmonary oedema and died. At

Table 2 Causes of late deaths ( $n=97$ (28\%) patients)

\begin{tabular}{ll}
\hline Causes & No (\%) of patients \\
\hline Cardiac: & $29(8.5)$ \\
Myocardial failure & $18(5)$ \\
Homograft failure & $15(4 \cdot 4)$ \\
Infective endocarditis & $4(1)$ \\
Miliary tuberculosis & $20(6)$ \\
Non-cardiac & $11(3)$ \\
Undetermined & \\
\hline
\end{tabular}

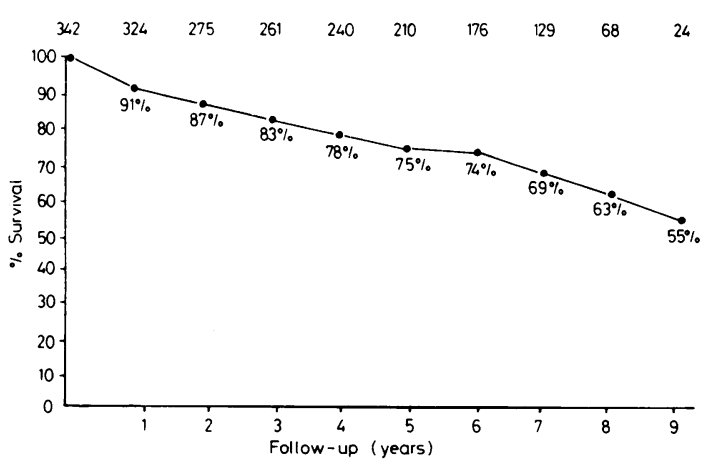

Fig. 4 Actuarial survival after mitral valve replacement using aortic homografts. Early deaths were excluded from analysis.



Fig. 5 Actuarial curve of probability of freedom from thromboembolism.

necropsy, the valve was found to be partly detached from the Dacron tube in three patients and in the fourth patient there was thrombus in the left atrium compressing the Dacron tube.

The remaining two patients developed gradual symptomatic deterioration $\mathbf{3 0}$ months after operation. They showed signs of predominant mitral stenosis, and at reoperation there was distortion of the Dacron tube producing functional stenosis, the valve cusps being normal. Both patients underwent replacement with Starr-Edwards prosthesis. One patient is alive and well and the other died in the immediate postoperative period.

\section{ENDOCARDITIS}

Nineteen patients $(5 \%)$ developed endocarditis. The probability of freedom from endocarditis at three years was $96 \%$, at five years $94 \%$, and at nine years 91\% (Fig. 6).

Fungal endocarditis occurred in 10 patients, and bacterial in six (Streptococcus viridans in four and 
Table 3 Micro-organisms causing endocarditis ( $n=19$ (5.5) patients)

\begin{tabular}{ll}
\hline Micro-organism & No of patients \\
\hline Fungal (Candida albicans and aspergillus) & 10 \\
Bacterial & 4 \\
Streptococcus viridans & 2 \\
Staphylococcus aureus & 3 \\
Undetermined & \\
\hline
\end{tabular}

Table 4 Latest sympomatic status of patients with original homograft ( $n=157$ patients)

\begin{tabular}{lllll}
\hline $\begin{array}{l}\text { NYHA } \\
\text { classification: }\end{array}$ & $I$ & $I I$ & $I I I$ & $I V$ \\
\hline No (\%) of patients & $104(66)$ & $41(26)$ & $11(7)$ & 1 \\
\hline
\end{tabular}

Mean follow up, 102 months; range 52-138 months.

Staphylococcus aureus in two). In the remaining three patients no organisms were isolated (Table 3 ).

Nine of the 19 patients underwent reoperation for haemodynamic sequelae of endocarditis when the homograft was replaced using a prosthetic valve. Four patients are alive and five died, four early and one late as a result of congestive cardiac failure. The remaining 10 patients who did not undergo reoperation all died.

\section{DEGENERATION}

Of the operative survivors, there were $43(12.5 \%)$ degenerative valve failures. The probability of freedom from degeneration was $97 \%$ at five years, $82 \%$ at eight years, and $48 \%$ at 10 years (Fig. 7). There was an increase in the rate of degeneration after the seventh year.

The predominant lesion was mitral regurgitation in all except four who had dominant stenosis. Clinical deterioration occurred over a period of a year or more in all these patients.

Thirty seven patients underwent replacement of the

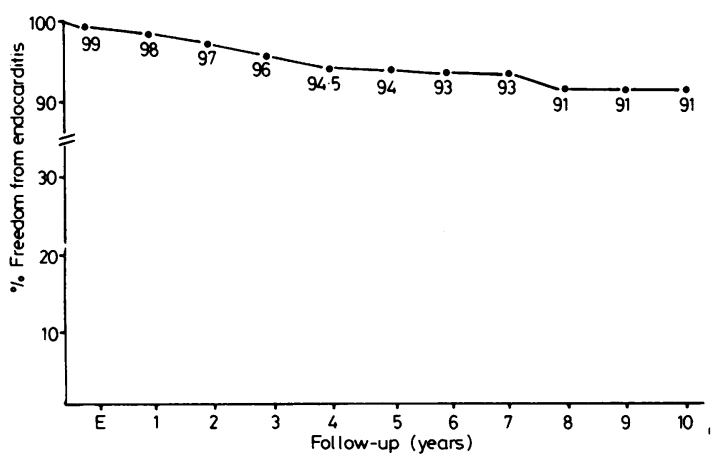

Fig. 6 Actuarial curve of probability of freedom from endocarditis.

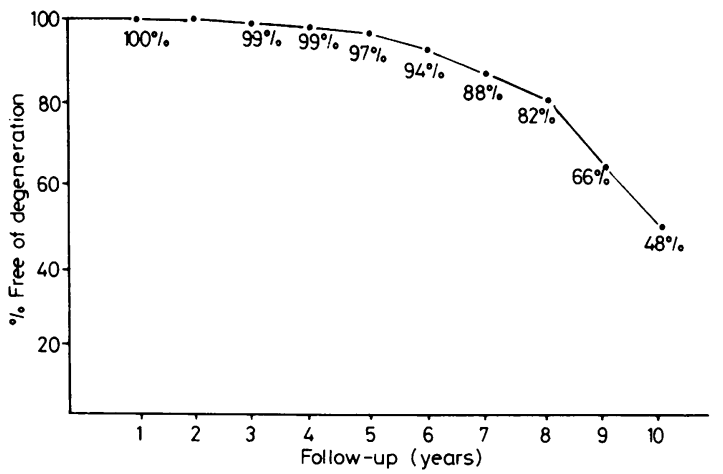

Fig. 7 Actuarial curve of probability of freedom from degeneration.

malfunctioning homograft using Starr-Edwards prosthesis. Of these patients, 30 are alive, four died early (an operative mortality of $11 \%$ ), and three died late, because of congestive cardiac failure in one, endocarditis in one, and undetermined cause in one.

The six patients who did not undergo reoperation all died.

\section{SYMPTOMATIC STATUS}

At a mean follow-up of 102 months (range 52 to 138 months), 192 patients were available for assessment. Of these, 157 (82\%) still have their original homograft valve and $35(18 \%)$ have had the homograft replaced by a prosthetic valve, at a mean of 86 months (range 10 to 124 months).

Of the patients with their original homograft, $66 \%$ are in NYHA classification class I, $26 \%$ are in class II, and $7 \%$ are in class III (Table 4). In the group of patients whose homograft has been replaced, $48.5 \%$ are in class $\mathrm{I}, 48.5 \%$ in class II, and $3 \%$ in class III.

\section{Discussion}

In an attempt to find the ideal substitute for the diseased mitral valve, the technique of using inverted antibiotic sterilised aortic homografts was developed in 1968. ${ }^{1}$ This technique, in theory, offers several advantages which include: (1) the lack of rigid stents which could interfere with left ventricular function and affect the durability of the homograft, (2) provision for smooth blood flow from the pulmonary veins into the homograft without any areas of stasis or turbulence; (3) the homograft placed entirely in the left atrium does not protrude into the left ventricular cavity; (4) all the prosthetic material is covered by autogenous pericardium or homograft tissue and does not come into contact with the circulation; (5) long-term anticoagulation is avoided.

The early and late mortality rates in this series 


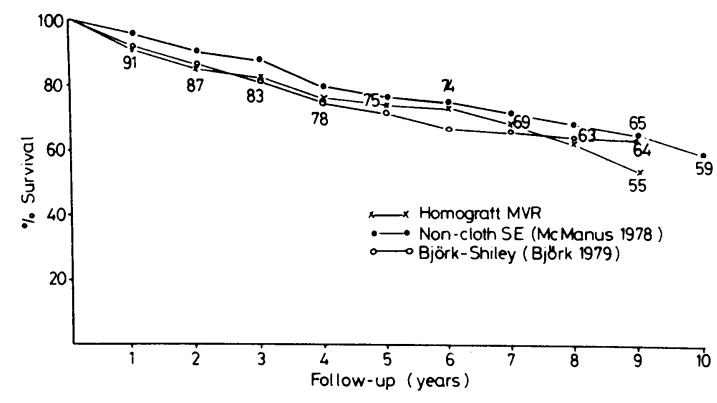

Fig. 8 Actuarial survival curves for patients undergoing aortic homograft replacement of mitral valve, comparing survival with patients undergoing mitral valve replacement with non-cloth covered Starr-Edwards prosthesis ${ }^{9}$ and Björk-Shiley prosthesis 10 reported in two separate series.

were similar to those reported for other types of tissue prostheses in the mitral position, ${ }^{7-9}$ and the pattern of survival after this type of valve substitute appears to be almost identical to that reported for prosthetic valves as shown in Fig. 8 which depicts long term survival for two large series, one using Starr-Edwards prosthesis ${ }^{10}$ and the other using Björk-Shiley valve. ${ }^{11}$

Despite the lack of anticoagulation, thromboembolism was uncommon. Valve degeneration and endocarditis, however, remained a problem. Valve degeneration could be monitored clinically, as it was always accompanied by a slow progression of symptoms allowing ample time for re-replacement. Regular evaluation is particularly important for the patients with valves implanted for seven years or more, since degeneration occurs at an increasing rate after this period. The incidence of degeneration is higher in the aortic homografts used in the mitral position than those in the aortic position. ${ }^{12}$ This may be because of different haemodynamic stresses in the two positions. The use of stented aortic homografts for mitral valve replacement led to early homograft failure, ${ }^{13}$ resulting from cusp prolapse or detachment. Mitral valve

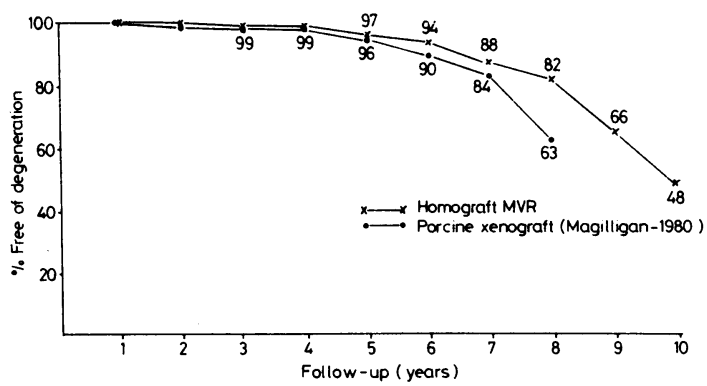

Fig. 9 Probability of freedom from degeneration in aortic homograft replacement of mitral valve compared with porcine xenograft replacement of mitral valve. ${ }^{14}$ replacement with other tissue valves has given satisfactory results for up to seven years. ${ }^{914-16}$ There is, however, still uncertainty about their behaviour for longer periods than that.

In a recent report of a large series of mitral valve replacement using porcine xenografts, ${ }^{15}$ the probability of freedom from degeneration was $63 \%$ at eight years compared with $82 \%$ in our series and there was an increase in degeneration after the sixth and seventh years (Fig. 9).

The aortic homograft is capable of satisfactory function for 10 or more years in some patients. Routine investigation of some of our patients at 10 years has shown normal function of the valves. The factors that govern the rate of homograft degeneration are unknown but may include: (1) the age of the donor; (2) methods of preparation and preservation; (3) methods of insertion; (4) immunological reaction resulting in a process of ongoing slow rejection.

Although in our series, no children were included, our experience with homograft replacement of the aortic valve ${ }^{17}$ has shown that the rate of degeneration was slower than that observed in adults possibly because of the lower arterial pressure in younger patients. From the data available, it appears that the use of unstented homografts in this age group could be the best currently available valve substitute, particularly in view of the difficulties of long term anticoagulation and the fact that porcine xenografts have an alarmingly high rate of degeneration in children. ${ }^{18} 19$

The incidence of endocarditis (5\%) in this series has been relatively high compared with that reported for mechanical prosthesis which varied from 0 to $4 \%$ in patients followed for shorter periods. ${ }^{20-22}$ The risk of endocarditis continued to increase during the period of follow-up. Early infection (within the first six months) accounted for about $40 \%$ of all cases of endocarditis. In these patients, the infection could have been the result of inadequate sterilisation of the homograft or introduced during the perioperative period. Routine culture of strips of homograft tissue at the time of operation did not grow any organisms in the patients who subsequently developed endocarditis. Though this does not rule out the possibility of inadequate sterilisation, it suggest that other causes of perioperative infection could play an important role.

Fungal endocarditis has continued to cause concern despite the use of antifungal agents in the homograft sterilising solution. The management of fungal endocarditis on homograft valves has been discussed in a previous paper. ${ }^{23}$

We have reported in detail the occurrence of miliary tuberculosis after homograft valve replacement. ${ }^{24}$ The source of infection was presumed to be valve contamination in the postmortem room. Since the 
addition of antituberculous drugs in the sterilising solution, this complication has not been encountered.

Homograft endocarditis carried an operative mortality of $44 \%$ for reoperation with an overall mortality of $79 \%$. The best results were obtained in the patients in whom the infection was successfully treated by antibiotics, followed by elective replacement of the malfunctioning homograft.

Reoperation as a result of valve failure resulting from degeneration carried a slightly increased operative mortality $(11 \%)$. This is partly because of the late referral of the patients. Over the past four years, because of earlier intervention, the operative mortality for reoperation is $6.2 \%$ (one death out of 16 patients). Familiarity with the technique of removing the homograft may have contributed to the improved operative mortality.

In adults, this valve has produced results similar to those with porcine xenografts, with perhaps a marginally slower rate of degeneration. One of the disadvantages of unstented homografts in the mitral position, however, is that their replacement constitutes a more involved procedure and requires familiarity with the exact method of insertion. In children the use of unstented homografts offers the advantage of the slowest rate of degeneration of tissue valves currently available. Though this form of valve replacement is now seldom used in adults in our institution, continued analysis of its long term performance and the factors that could influence it are being made in an attempt to define its role in the future.

\section{References}

1 Yacoub $\mathrm{MH}$, Kittle CF. A new technique for replacement of the mitral valve by a semilunar valve homograft. f Thorac Cardiovasc Surg 1969; 58: 859-69.

2 Yacoub MH, Knight E, Towers MK. Aortic valve replacement using fresh unstented homografts. Thoraxchirurgie 1973; 21: 451-7.

3 Yacoub MH, Kittle CF. Sterilization of valve homografts by antibiotic solutions. Circulation 1970; 41 (suppl II): 29-31.

4 Yacoub MH, Knight E, Towers MK. Late results of mitral valve replacement using "fresh" unstented aortic homografts. Thoraxchirurgie 1973; 21: 458-64.

5 Berkson J, Gage RP. Calculation of survival rates for cancer. Procedings of the Staff Meetings of the Mayo Clinic 1950; 25: 270-86.

6 Bodner E, Haberman S, Wain WH. Comparative method of actuarial analysis of cardiac valve replacements. Br Heart f 1979; 42: 541-52.

7 Lepley D Jr, Flemma RJ, Mullen DC, Motl M, Anderson AJ, Weirauch E. Long term follow up of BjörkShiley prosthetic valve used in the mitral position. Ann Thorac Surg 1980; 30: 164-72.

8 Grehl TM, Naifeh JG, Broda J, Dajee A, Hurley EJ. Heterograft cardiac valve prostheses: a five year follow up. Ann Thorac Surg 1980; 30: 173-6.

9 Tandon AP, Sengupta SM, Lukacs L, Ionescu MI. Long term clinical and hemodynamic evaluation of the Ionescu-Shiley pericardial xenograft and the Braunwald-Cutter and Björk-Shiley prostheses in the mitral position. F Thorac Cardiovasc Surg 1978; 76: 76370.

10 MacManus Q, Grunkemeier GL, Lambert LE, Starr A. Non-cloth covered caged-ball prostheses-the second decade. $F$ Thorac Cardiovasc Surg 1978; 76: 788-94.

11 Björk VO, Henze A. Ten years' experience with the Björk-Shiley tilting disc valve. F Thorac Cardiovasc Surg 1979; 78: 331-42.

12 Thompson RH, Yacoub MH, Ahmed MS, Somerville W, Towers MK. The use of 'fresh' unstented homograft valves for replacement of the aortic valve. Analysis of 8 years experience. $\mathcal{F}$ Thorac Cardiovasc Surg 1980; 79: 896-903.

13 Oh W, Somerville J, Ross DN, Ross JK, Emanuel R. Mitral valve replacement with preserved cadaveric aortic homografts. F Thorac Cardiovasc Surg 1973; 65: 712-21.

14 Oyer PE, Craig-Miller D, Stinson EB, Reitz BA, Moreno-Cabral RJ, Shumway NE. Clinical durability of the Hancock Porcine bioprosthetic valve. $\mathcal{F}$ Thorac Cardiovasc Surg 1980; 80: 824-33.

15 Magilligan DJ Jr, Lewis JW Jr, Jara FM, et al. Spontaneous degeneration of porcine bioprosthetic valves. Ann Thorac Surg 1980; 30: 259-66.

16 Lakier JB, Khaja F, Magilligan DJ Jr, Goldstein S. Porcine xenograft valves-long term (60-89 month) follow up. Circulation 1980; 62: 313-8.

17 Radley-Smith R, Fagan A, Yacoub MH. An eleven year experience of fresh aortic homograft replacement in children [Abstract]. Am $\mathcal{F}$ Cardiol 1982; 49: 1035.

18 Sanders S, Levy RJ, Freed MD, Norwood WI, Castaneda AR. Use of Hancock Porcine xenografts in children and adolescents. Am $\mathcal{F}$ Cardiol 1980; 46: 429-38.

19 Kutsche LM, Oyer PE, Shumway N, Baum D. An important complication of Hancock mitral valve replacement in children. Circulation 1979; 60 (suppl. I): 98-103.

20 Slaughter L, Morris JE, Starr A. Prosthetic valvular endocarditis. A 12 year review. Circulation 1973; 47: 1319-26.

21 Rossiter SJ, Stinson EB, Oyer PE, et al. Prosthetic valve endocarditis - comparison of heterograft tissue valves and mechanical valves. $\mathcal{F}$ Thorac Cardiovasc Surg 1978; 76: 795-803.

22 Masur H, Johnson WD Jr. Prosthetic valve endocarditis. f Thorac Cardiovasc Surg 1980; 80: 31-7.

23 Wain W, Ahmed MS, Thompson RH, Yacoub MH. The role of chemotherapy in the management of fungal endocarditis following homograft valve replacement. Postgrad Med f 1979; 55: 629-31.

24 Anyanwu $\mathrm{CH}$, Nassau E, Yacoub MH. Miliary tuberculosis following homograft valve replacement. Thorax 1976; 31: 101-6.

Requests for reprints to Mr M H Yacoub, FRCS, Harefield Hospital, Harefield, Uxbridge, Middlesex UB9 6JH. 